\title{
TÁIN BÓ CÚAILNGE: VERSÕES E BACKGROUND HISTÓRICO
}

\section{Erik Wroblewski}

RESUMO: A Táin Bó Cúailnge, ou "Razia das Vacas de Cooley” é uma produção literária de caráter mitológico que retrata elementos estruturais da sociedade céltica Tardo Antiga e Medieval, e que mesmo após o processo de cristianização de suas narrativas, mantém referências à cultura pré-cristã que a produziu. Permanecem, atualmente, duas versões conhecidas: a "Táin Rescencion I", encontrada no "Livro da Dun Cow" e a "Táin Rescencion II" encontrada no "Livro de Leinster". Neste artigo, iremos analisar o contexto de produção da versão mais recente e as possíveis motivações de seu redator em relação a esta obra.

PALAVRAS-CHAVE: Táin Bó Cúailnge; Sociedade Céltica; Irlanda Tardo Antiga.

\section{Introdução}

A Táin Bó Cúailnge, ou "Razia das Vacas de Cooley”, é uma narrativa épica irlandesa, cujas versões conhecidas datam dos sécs. XI e XII, respectivamente, muito embora "referências poéticas da Táin possam ser encontradas em poemas que se acredita datarem do século VII; uma dessas referências está preservada num manuscrito datado de aproximadamente 750 d.C.”1 e estudos lingüísticos e literários não conclusivos apontem para uma maior ancestralidade de suas estruturas narrativas; "em geral, a Língua dos textos é muito mais antiga que a data da transcrição e, quando a Língua é renovada por

\footnotetext{
${ }^{1}$ WILSON, David Noel, citando a introdução da Táin Bó Cúailnge Recension 1, compilada por Cecile O'Rahily. Honour and Early Irish Society: a Study of Táin Bó Cúailnge, p. 20
} 
uma transcrição recente, é raro não subsistirem vestígios ou formas de palavras antigas". ${ }^{2}$

A despeito disso, embora as estruturas descritas no épico tenham sido cristianizadas e tenham recebido adições ou sofrido algumas alterações de acordo com o contexto histórico de quando foram reescritas ${ }^{3}$, ainda descrevem um comportamento social arcaico ${ }^{4}$, que podemos verificar ao compará-las com aquelas descritas por autores clássicos, sobretudo César.

A Táin Bó Cúailnge faz parte do corpo literário conhecido como "Ciclo de Ulster", que descreve os feitos dos Ulaid, ou "Pessoas de Ulster", e é a mais longa e importante narrativa do "ciclo". Ela descreve a mobilização das cóiced ou "províncias" de Mide, Connaught, Munster e Leinster contra a cóicedi de Ulster, sob o comando da rainha Medb e do rei Ailill, soberanos de Connaught, com o fim de se apossar de Donn Cúailnge, um touro gigante e mágico que pertence aos homens de Ulster.

A narrativa se desenrola em um passado heróico distante, onde divindades pagãs e pessoas da Sídh (o "Outro Mundo") interagem com as personagens da narrativa, onde essas personagens algumas vezes possuem estaturas gigantescas ou habilidades super-humanas e figuram no cenário criaturas mágicas e fantásticas. Em muitos aspectos, a Táin guarda aspectos de um "mito de criação", pois muitas dessas figuras apresentadas na narrativa são as responsáveis pela criação ou nomeação de localidades e acidentes geográficos importantes. $^{5}$

\footnotetext{
${ }^{2}$ LE ROUX, Françoise e GUYONVARC’H, Crhuistian-J. A Civilização Celta, p. 43

${ }^{3}$ WILSON, David Noel. Honour and Early Irish Society: a Study of Táin Bó Cúailnge, p. 24

${ }^{4}$ LE ROUX, Françoise e GUYONVARC'H, Crhuistian-J. A Civilização Celta, p. 45.

${ }^{5}$ WILSON, David Noel. Honour and Early Irish Society: a Study of Táin Bó Cúailnge, p. 19, 44.
} 
Tradicionalmente, costuma-se atribuir a narrativa da Táin à idealização de uma perspectiva do ponto de vista guerreiro, uma celebração à coragem e habilidade marcial. No entanto, através de uma crítica mais aprofundada, podemos perceber que sua estrutura se trata de uma mistura da tradição oral pagã com elementos dos ensinamentos cristãos, criando ironias e paradoxos bem claros no decorrer do texto, que representam um "rompimento trágico" com os valores sociais da Irlanda antiga, no qual está fundamentada: "Por trás da imensa vitalidade humor e imaginação das narrativas do Ciclo de Ulster há uma imagem da sociedade movendo-se rumo à disfunção e auto-destruição". 6

A recorrência de temas como honra, valor, fidelidade e a validade da soberania também são recorrentes, demonstrando a sua importância na narrativa.Embora ambas as versões tratem do mesmo episódio - a razia de vacas que mobilizou quatro "províncias" da Irlanda contra uma quinta - existem importantes diferenças estruturais importantes entre os dois documentos.

A primeira destas versões é o Táin Bó Cúailnge Recension 1, escrita por volta do ano 1100, e encontra-se no manuscrito Lebor na hUidre. Foi compilada por Muire Mac Céilechar, indivíduo do qual pouco se conhece. Esta versão inclui diversos episódios repetidos, em diferentes variações, o que leva a crer que seu autor estava mais preocupado em reproduzir o conteúdo tradicional do que organizá-lo em um corpo estrutural coerente.

A segunda versão, e a que nos interessa mais, é a Táin Bó Cúailnge LL, encontrada no Livro de Leinster, e escrita entre 1151 e 1201, a qual é mais bem documentada e completa. Seu autor, Áed Úa Crimthainn, preocupou-se em organizar os “eventos” da Táin em uma estrutura seqüencial e mais inteligível, produzindo uma narrativa mais unificada. Áed, por sua vez, era provavelmente o historiador-chefe do

6 "Behind the immense vitality, humor and imagination of the Ulster stories is a picture of society moving to dysfunction and self-destruction." RADNER, Joan N. 'Fury Destroys the World' Historical Strategy in Ireland's Ulster Epic. Mankind Quarterly 23, p. 41. 
rei de Leinster, Diarmait Mac Murchada, e também o último abade de Tír Dá Glas (Terryglass) em Tipperary.

Além da organização, a Táin LL conta a inserção de uma "introdução" à narrativa, conhecida como Pillow Talk ou "Conversa de Travesseiro", que descreve os motivos para a mobilização dos "Homens da Irlanda" na razia contra a cóiced de Ulster, inexistente na Táin 1, que se inicia já com as tropas marchando sob o comando da Rainha Medb, descreve mais episódios do que a outra versão, e suas personagens são mais estilizadas e idealizadas. Também possui um colofão em latim, que se destaca do restante do texto, escrito em gaélico.

Por fim, a narrativa da Táin LL estrutura-se num caráter muito mais negativo e pessimista do que a na da Táin 1, especialmente no que se refere à descrição da Rainha Medb, que é apresentada como a antítese de todos os valores "tradicionais" de comportamento guerreiro e de soberania. A conclusão da Táin LL também é muito mais pessimista: na ocasião da conclusão da narrativa, não há uma paz após a guerra, e o touro mágico, Donn Cúailnge se volta contra as mulheres e crianças de Ulster, matando-as de depois morrendo de tristeza.

Esses elementos são marcantes e emblemáticos quando analisados à luz dos eventos históricos irlandeses do séc. XII, sobretudo aqueles que envolvem a vida do autor do Livro de Leinster, que acabam por refletir os valores tradicionais de uma sociedade que se vê em vias de extinção frente ao processo de cristianização da Irlanda.

\section{Contexto Histórico de Produção da Táin}

Desde o séc. V, as instituições eclesiásticas irlandesas eram fundadas e mantidas por nobrezas locais com o intuito de legitimar e manter o poder dos "reis de cantão" (Túath) e de "províncias"

${ }^{7}$ WILSON, David Noel. Honour and Early Irish Society: a Study of Táin Bó Cúailnge, p. 20. 
(Cóiced) e de fortalecer a cultura local nos constantes embates políticos entre "reinos". Os territórios destas instituições eram de caráter hereditário, e as posições de comando eram indicadas pelas lideranças das famílias às quais elas estavam ligadas. Esse tipo de organização ficou conhecida como paruchiae. O caráter de sua produção literária indica que sãs paruchiae se desenvolveram de forma a conservar tanto a tradição literária irlandesa de fundo pagão (que muitas vezes traçava a linhagem mítica das famílias nobres), quanto de disseminar os ensinamentos cristãos.

Esse tipo de produção indica que estes literatos e estudiosos não faziam distinção entre o conhecimento tradicional e o latino, como atestam muitos dos obituários da época, que freqüentemente se preocupavam em ilustrar com clareza o conhecimento dos falecidos tanto em uma quanto na outra "área"8. Ademais, também implica que só era possível na medida em que era tolerado pelas autoridades eclesiásticas.

No entanto, a partir do séc. VII inicia-se um debate entre duas tendências ou "tradições" da Igreja Católica Irlandesa, os Hibernenses, organizados em torno da paruchiae, e defensores deste sistema, e os Romani, que representavam a ortodoxia advinda do Vaticano e eram muito menos tolerantes à manutenção dessa tradição literária de origem "pagã" ${ }^{10}$ Além de defender a exclusão desses elementos "heréticos", a tendência Romani irá buscar a unificação da Igreja sob uma autoridade central, já que via na interferência da nobreza nas instituições monásticas um "abuso" contra a Igreja. ${ }^{11}$ Durante os sécs. VIII e IX, a Sé de Armagh irá se tornar o principal ponto de irradiação dessa tendência "romanizante", buscando organizar a Igreja Irlandesa de acordo com os moldes europeus

\footnotetext{
${ }^{8}$ McCONE, Kim. Pagan Past and Christian Present in Early Irish Literature. p. 26.

${ }^{9}$ Ó CÓRRAIN, Dáibhí. Early Medieval Ireland 400-1200. p. 150-152.

${ }^{10}$ Ibid. p. 24.

${ }^{11}$ WILSON, David Noel. Honour and Early Irish Society: a Study of Táin Bó Cúailnge, p. 26.
} 
atendendo a pretensões de se tornar a autoridade secular central da ilha.

No campo político, veremos que a partir do séc. VII a dinastia dos Ulaid, (Ulster) verá seu poder e influência decair lentamente, enquanto o poder e a influência de outras dinastias irão afirmar-se cada vez mais. Mais adiante, durante os sécs. VIII e IX conforme nos mostram as entradas nos Anais de Ulster, veremos que "reis de cantões" e "reis de província" começarão a angariar poder político e militar ao seu redor, em detrimento de unidades políticas menores. ${ }^{12}$

Durante o fim do séc. IX, Máel Sechmaill irá unificar a dinastia dos Úi Néill, após derrotar inimigos vikings e irlandeses em 846 e irá iniciar uma campanha expansionista que com a pretensão de unificar a Irlanda sob seu comando. Para isso, irá se valer do argumento da autoridade tradicional de sua dinastia sucessora dos "grandes reis de Tara"13. Durante esse período, a Dinastia Úi Néill irá apoiar a Sé de Armagh em suas pretensões de unificação eclesiástica, assim como o Abade de Armagh irá posicionar a tendência romani a favor das pretensões dos Úi Neill. ${ }^{14}$

Essa cooperação se manteve nos séculos seguintes, enquanto a dinastia dos Úi Néill aumentava seu poder, e expandia territórios utilizando-se de mercenários normandos e apoiando as reformas eclesiásticas empreendidas pela Sé de Armagh. Por sua vez, a centralização do poder da Igreja atendia a "causa" dos Úi Néill, na medida em que, ao remover o poder de indicar seus próprios seguidores as posições mais elevadas nos mosteiros, a "baixa

\footnotetext{
${ }^{12}$ Anals of Ulster, anos 779 a 793, e HERBERT, Máire. Rí Éirenn, Rí Alban, kingship and identity in the ninth and tenth centuries. Em Kings, clarics and chronicles in Scotland. p. 62.

${ }^{13}$ HERBERT, Máire. Rí Éirenn, Rí Alban, kingship and identity in the ninth and tenth centuries. Em Kings, clarics and chronicles in Scotland. p. 63.

${ }^{14}$ Anals of Ulster, anos 823 a 847, HERBERT, Máire. Rí Éirenn, Rí Alban, kingship and identity in the ninth and tenth centuries. Em Kings, clarics and chronicles in Scotland. Pág. 63 e ${ }^{14}$ WILSON, David Noel. Honour and Early Irish Society: a Study of Táin Bó Cúailnge, p. 25.
} 
nobreza” via sua influência política e cultural e também sua riqueza diminuídas e fragilizadas. ${ }^{15}$

Este processo chega ao seu ápice no séc. XII, quando a tolerância à manutenção da tradição literária irlandesa se vê ameaçada não somente pelo fortalecimento e centralização política e religiosa, mas também intolerância a essa mesma tradição por parte dos normandos, cujo estado de ocupação já era avançado, sobretudo na porção Sul e Leste da Ilha. Esse processo será determinante na composição da Táin LL, uma vez que seu autor será profundamente afetado por ele.

Em 1164, o mosteiro de Tír Dá Glas, do qual Áed era o abade chefe é incendiado durante um dos muitos conflitos entre Diarmait e seus vizinhos. Por volta de 1166, Diarmait Mac Murchada será expulso de seu reino e exilado da Irlanda por seus inimigos, o que causou um grande impacto em Áed, conforme ele nos mostra em uma nota deixada no Livro de Leinster:

O King of Heaven, dreadful is the deed that has been perpetuated today (ie. The kalands of August), namely, Diarmait son of Donnchad Mac Murchada, King of Leinster and the foreigners (i.e., Dublin, Danes) has been banished over the sea by the men of Ireland. Alas, alas, O Lord what shall I do? ${ }^{16}$

Em seu exílio na Escócia e em Gales, Diarmait recruta mercenários normandos, com o intuito de reconquistar seu reino, objetivo que atinge em 1170 . No entanto, morrerá logo em seguida, deixando a cóiced de Leinster sob o julgo normando, encabeçado pela figura de Richard de Clare "Strongbow". Áed, claramente inclinado à uma perspectiva hibernense, jamais verá seu mosteiro reconstruído, estando por conta própria ao compilar o Livro de Leinster, em meio a todas as intolerâncias à tradição literária irlandesa, advindas tanto dos irlandeses quanto dos normandos, o que muito provavelmente se refletiu nas perspectivas pessimistas que apresenta nas narrativas.

\footnotetext{
${ }^{15}$ Ibid.

${ }^{16}$ Book of Lainster, XVII.
} 


\section{Autor e Obra: algumas aproximações e críticas “literárias” à Táin LL}

A "literatura heróica" trata-se de um "gênero" literário peculiar, cujas "regras” não precisam, não podem ou não devem coincidir com a realidade. Seu caráter fantástico não as torna plausíveis nem ao menos de refletir diretamente a realidade social dentro da qual foram concebidas. No entanto, como observado por M. Redfild, "as narrativas devem se conformar suficientemente à realidade social para que sejam inteligíveis às suas audiências"17.

Assim, como diz David N. Wilson em sua dissertação Honour and Early Irish Society: a Study of Táin Bó Cúailnge,

eu argumento que as narrações não eram intencionadas apenas como mero entretenimento, mas como instrumentos de transmissão de valores culturais. Elas formavam parte do método de transmissão cultural de valores e atitudes. A Arte pode dirigir a vida: Cú Chulainn estaria contente em ter 'apenas um dia e uma noite no mundo desde que minha fama e meus feitos vivam depois de mim' (Táin LL, 164). Contudo, seus feitos podem viver apenas nas estórias, poemas ou nas músicas. Cú Chulainn estaria representando a visão de fama e renome de sua cultura, ainda que de uma maneira extrema. O impacto cultural nas narrativas era para reportar e moldar comportamentos. Os reis, a nobreza e os guerreiros da Irlanda medieval se comportavam como se aceitassem os valores e atitudes dos épicos heróicos? Parece que sim. Na Irlanda Antiga e Medieval era esperado que os reis liderassem suas tropas do front, e muitos morreram em batalha. 18

Nós aceitamos a mesma posição, e procuraremos explicar como, embora a construção da narrativa da Táin Bó Cúailnge tenha sido um processo gradual, ocorrido provavelmente durante cinco séculos, através do qual diversas “camadas extras” de valores sociais,

${ }^{17}$ Citado em WILSON, David Noel. Honour and Early Irish Society: a Study of Táin Bó Cúailnge, p. 22.

${ }^{18}$ Ibid. 
eventos históricos e preocupações ideológicas diferentes tenham sido adicionadas ao texto "original”, ele ainda mantém valores e posições mais arcaicas em sua estrutura, sobretudo no que se refere à versão que escolhemos para este estudo, a Táin LL, pois ela representa o ápice de um processo pelo qual esses mesmo valores "tradicionais" vêm sendo ameaçados e portanto, precisavam ser registrados.

Com este intuito, iremos elaborar uma aproximação crítica e "literária" a esta narrativa para, em um primeiro momento identificar suas estruturas e valores fundamentais, e em seguida comparar estes mesmos elementos com o período histórico no qual foi elaborada, buscando então identificar quais são as percepções que seu autor poderia ter da realidade social e política em que vivia e que valores poderia estar defendendo.

Numa breve análise, vemos que a estrutura literária apresentada pela Táin LL deixa implícita a existência de duas "audiências” da narrativa: primeiramente, há a "audiência interna”, ou seja, as personagens da narrativa, para as quais as ações heróicas são realizadas $^{19}$, e sem as quais (como quando uma personagem está sozinha na narrativa), existe a possibilidade de uma ação que esteja em desacordo com os valores sociais vigentes.

Isso se explica na medida em que a sociedade "céltica" estaria fundamentada em estritos códigos de conduta, os quais eram responsáveis por determinar o "valor" ou "preço de honra". A honra é um conceito complexo, que varia de sociedade para sociedade, mas que está ligado a noções de respeito, reverência, riqueza e posição social, todas elas informadas através da tradição, respeitadas e reguladas por um consenso social ${ }^{20}$.

Trata-se de um mecanismo de controle empregado por sociedades que não possuem um sistema de coerção instituído, servindo para regular as ações dos indivíduos, ao menos na esfera

19 O’LEARY, Philip. Choice and Consequence in Irish Heroic Literature. Cambrian Medieval Studies 27. p. 49.

${ }^{20}$ WILSON, David Noel. Honour and Early Irish Society: a Study of Táin Bó Cúailnge, p. 14. 
pública. Sociedades assim constituídas são complexas, e se inscrevem e se organizam em torno de sistemas jurídicos ou de jurisprudência muito elaborados, que determinam as atitudes necessárias ao indivíduo de acordo com sua riqueza e posição social.

Se respeitadas, essas atitudes demonstram reciprocidade do indivíduo em relação à sociedade, e acarretam em seu respeito e na elevação do "nível” de honra do indivíduo. Se não observadas as posturas necessárias à sua posição, o indivíduo rompe com o "pacto social" e vê sua honra diminuída, podendo ser alvo de pedidos de restituição por ofensas ou punições ainda piores.

Sociedades como estas são conhecidas como "sociedades baseadas em honra" ${ }^{21}$, e uma das principais características de tais sociedades é a mobilidade social. Ao observar as instituições da Irlanda Medieval e Antiga, e a preocupação em determinar quais as ações apropriadas a um indivíduo nas recolhas jurídicas como o Senchus Már e, sobretudo sobre as complexas elaborações à respeito dos "preços de honra", podemos afirmar que essas instituições se baseiam em preocupações de uma sociedade de honra.

A "segunda audiência” é aquela representada pelos ouvintes da narrativa, contemporâneos do momento em que está sendo recitada, os quais estariam mais interessados nos problemas éticos e psicológicos enfrentados pelas personagens em sua busca de balancear sua honra pessoal e suas obrigações sociais, sem dar muita importância aos motivos pelos quais estes conflitos ocorrem ${ }^{22}$, e à qual esta narrativa pretende transmitir valores sociais e ideológicos.

Outro elemento muito marcante, presente na Táin LL, é o colofão em latim, escrito por seu autor logo após o término da transcrição da narrativa, merecendo uma atenção mais aprofundada. Esse colofão foi alvo de um debate realizado por um artigo escrito por

\footnotetext{
${ }^{21}$ CHARLES-EDWARDS, Thomas M. Early Christian Ireland. p. 136.

${ }^{22}$ O'LEARY, Philip. Choice and Consequence in Irish Heroic Literature. Cambrian Medieval Studies 27. p. 49.
} 
Pádraig Ó Néill ${ }^{23}$, ao qual procuraremos esclarecer aqui, e então acrescentar nossas próprias percepções acerca desta passagem:

Sed ego qui scripsi hanc historiam aut uerius quibusdam fidem in hac historia aut fabula non accommodo. Quaedam enim ibi sunt praestrigia demonum. Quaedam autem figmenta poética. Quaedam similia uéro. Quaedam non. Quaedam ad delectionem stultorum. ${ }^{24}$

Uma primeira interpretação desta passagem poderia nos remeter a um clérigo medieval de mente estreita intolerante à tradição pagã. No entanto, uma explicação dessas não condiziria com a verdade, especialmente ao lembrarmos as "filiações ideológicas" de seu autor. Além disso, sua extensa preocupação em compilar, por mais de 50 anos de sua vida, os épicos que constituem o Livro de Leinster, no qual organizou as narrativas, estendeu as genealogias e preencheu lacunas providenciando pontos de ligação entre trechos importantes dos textos, demonstram um mínimo de respeito pela tradição literária à qual dedicou seus esforços.

Ó Néill:

Então, o que o teria levado a escrever este colofão? Segundo

o julgamento da Táin foi baseado não em critérios eclesiásticos, mas em critérios retóricos. Um tal critério estava em sua mente como é indicado ao final do colofão, ad delectationem (stultorum), o qual relembra um dos objetivos declarados da retórica, deleitar o ouvinte. Mas eles são claramente revelados na terminologia retórica a qual ele usa para caracterizar certos outros incidentes da Táin como similia/non similia

${ }^{23}$ Ó NÉILL, Pádraig. The Latin Colophon to the Táin Bó Cúailnge in the Book of Leinster: A critical view of Old Irish Literature. Celtica 23, p. 269-275.

24 But I who have copied this historia or, more accurately, fabula, do not give credence to certain things in this historia or fabula. For certain things in it are the illusions of demons; certain are poetic ficctions; certain are plausible, certain are not; certain are for the entertainment of fools. Táin Bó Cúailnge from the Book of Lainster. p. 466. 
uero; e novamente quando ele debate se deve categorizar o trabalho como hitoria ou fabula. Todos esses termos pertencem ao vocabulário teórico. ${ }^{25}$

Essa posição se evidencia ainda mais pela forma como o colofão foi escrito: após o término da narrativa da Táin, toda realizada em gaélico, Áed “pula” algumas “linhas” e inicia essa passagem em latim, usando um parágrafo bem demarcado, com um caractere capitular decorado. Isso poderia atender a dois objetivos: primeiro, justificar a validade de seu trabalho frente às autoridades eclesiásticas, agora intolerantes à tradição "oral” de fundo "pagão, que contava com seu próprio colofão no início do texto: "Uma bênção a cada um que fielmente memorizar a Táin como ela está aqui escrita e não adicionar nenhuma outra coisa a ela” ${ }^{26}$, apelação esta que nos sugere que já não havia mais garantias, do séc. XII em diante, que houvesse uma fiel transmissão destas tradições ${ }^{27}$.

Segundo, o colofão em latim serviria para demarcar não um distanciamento religioso, mas sim um distanciamento mental, de tradições literárias e de pensamentos retóricos. "Provavelmente, ele assim o fez para distinguir este comentário pessoal do público em geral, ou para garantir que apenas aqueles que fossem versadom em

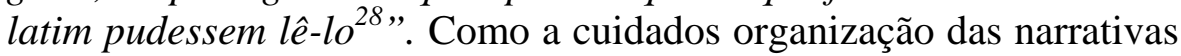
e genealogias do Livro de Leinster, a adição de “pontes” que ligam estas narrativas, e a forma cuidadosa e elaborada como seus caracteres foram gravados, nos sugere que Áed tratava-se mais se um estudioso e sabido do que um copista "profissional ${ }^{29 \text { ". }}$

Outro ponto fundamental a debater a respeito dessa passagem refere-se à "dúvida” do abade em classificar seu trabalho como historia ou fabula. Isso se deve ao motivo de que já era tradição

${ }^{25}$ Ó NÉILL, Pádraig. The Latin Colophon to the Táin Bó Cúailnge in the Book of Leinster: A critical view of Old Irish Literature. Celtica 23, p. 273.

${ }^{26}$ Táin Bó Cúailnge from the Book of Lainster. p. 272.

${ }^{27}$ Ó NÉILL, Pádraig. The Latin Colophon to the Táin Bó Cúailnge in the Book of Leinster: A critical view of Old Irish Literature. Celtica 23, p. 270

${ }^{28}$ Ibid. p. 271.

${ }^{29}$ Ibid. p. 270-275. 
instituída e suportada pela Igreja, ligar eventos mitológicos a eventos bíblicos para afirmar a descendência cristã dos habitantes da Irlanda, os quais eram transcritos nos vários anais irlandeses. Áed teria encontrado diversas formas de suporte nestes anais, que sempre foram elaborados por instituições monásticas, e em especial nos Anais de Ulster, para justificar coerentemente sua posição de classificar a Táin como historia, assim como o fez com a Togáil Trói, sua versão para a Guerra de Tróia contida no Livro de Leinster. E também não devemos nos esquecer do "julgo" normando em Leinster, à época da conclusão da Táin, que ao exemplo da Igreja Irlandesa, tornava-se cada vez menos tolerante à existência de tais relatos.

Assim, nos argumentamos que, sendo Áed o "historiador" chefe de Diarmait Mac Murchada e Abade de Tí Dá Glás, podemos concluir que além de ter tido uma longa educação formal, latina, muito provavelmente pertencia à nobreza, tendo sido indicado por seu rei para ambos os cargos que ocupava. Seu intuito, com este colofão era, aos nossos olhos, muito mais do que demarcar um distanciamento "mental": era sim buscar uma forma de se proteger de possíveis reações eclesiásticas à sua obra, ou a represálias por parte de algum rei (e em especial, um rei normando), que se pudesse identificar com as figuras da narrativa, caso esta fosse classificada como historia.

É por esse motivo, também, que argumentamos que a figura cujas características mais marcantes de desonra, deslealdade e incompetência, é a da rainha Medb: poucas mulheres foram citadas nos anais ${ }^{30}$, especialmente ocupando algum papel de preponderância nas narrativas cristianizadas. Ao fazer isso, Áed teria garantido que nenhum rei da época se identificasse com os atributos negativos da realeza apresentados por ele, ainda que demonstrasse claramente quais eram suas percepções acerca da soberania através de Medb e outras personagens e eventos da Táin ${ }^{31}$.

\footnotetext{
${ }^{30}$ HERBERT, Máire. Rí Éirenn, Rí Alban, kingship and identity in the ninth and tenth centuries. Em Kings, clarics and chronicles in Scotland., p. 68

${ }^{31}$ KELLY, Patricia. Táis as Literature. Pág. 78
} 


\section{BIBLIOGRAFIA}

Corpus iuris hibernici: ad fidem codicum manuscriptorum recognovit. Edited and translated by D. A. Binchy. Dublin: Institiúid Ard-Léinn Bhaile Átha Cliath, 1978.

Táin Bó Cúalnge from the Book of Leinster. Compilado por Donnchadh Ó Córrain. CELT: Corpus of Eletronic Texts: a Project from University College Cork. Cork, 2000.

CAESAR, Caius Julius. De Bellu Gallico. The Project Gutenberg, 2004. www.projectgutenberg.org

ARNOLD, Bettina \& GIBSON, D. Blair. Celtic Chiefdom, Celtic State. New Directions in Archeology. Cambridge University Press. Cambridge, 1995.

CHADWICK, Nora. The Celts. With an introductory chapter by J. X. W. P. Corcoran. London: Penguin, 1991.

CHARLES-EDWARDS, Thomas M. Early Christian Ireland. Cambridge: Cambridge University Press, 2000.

ELIADE, Mircea. Aspectos do Mito. Edições 70. Lisboa, 1989.

KELLY, Fergus. A Guide to Early Irish Law. Dublin: Dublin Institute for Advanced Studies, 1988.

KELLY, Patricia. The Táin as Literature. Em Aspects of the Táin. Ed. J. P. Mallory, 60-102. The University Press: Belfast, 1992.

GUERRIETS, Marilyn. Theft, Penitentials and the Early Irish Laws. Celtica 22. Dublin Institute for Advanced Studies. Dublin, 1991. GUYONVARC’H, Christian \& LE ROUX, Françoise. A Civilização Celta. Lisboa: Publicações Europa-América, 1999.

Europa-América, 1995.

A Sociedade Celta. Lisboa: Publicações 
HERBERT, Máire. 'Rí Éirinn, Rí Alban, kingship and identity in the ninth and tenth centuries'. In Taylor, S. (Editor). Kings, clerics and chronicles in Scotland. Four Courts: Dublin, 2000.

Ó CORRÁIN, Donncha. ed. "The early Irish Church: some aspects of Organisation." In Irish Antiquity: essays and studies presented to Professor, M. J. O’Kelly. Cork: Tower Books, 1981.

O'LEARY, Philip. Choice and Consequence in Irish Heroic Literature. Cambrian Medieval Studies

Ó NÉILL, Pádraig. The Latin Colophon to the Táin Bó Cúailnge in the Book of Lainster: a Critical View of Old Irish Literature. Celtica 23. Dublin Institute for Advanced Studies. Dublin, 1999.

NAGY, Joseph Falaky. Orality in Medieval Irish Narrative: An Overview. Oral Tradition 1/2, 1986.

RADNER, Joan N. Early Irish Hitoriography and the Significance of Form. Celtica 23. Dublin Institute for Advanced Studies. Dublin, 1999.

WILSON, David Noel. Honour and Early Irish Society: a Study of the Táin Bó Cúailnge. Tese apresentada ao departamento de História da Universidade de Melbourne. Melbourne, 2004.

ZEIDLER, J. Ancient and Medieval Celtic Myths of Origin. $17^{\text {th }}$ Irish Conference of Medievalists. Kieran's College. Killerny, 2003. 